\title{
BACTÉRIAS DIAZOTRÓFICAS EM MUDAS DE BANANEIRA ${ }^{1}$
}

\author{
OLMAR BALLER WEBER ${ }^{2}$, JOSÉ IVO BALDANI ${ }^{3}$ e JOHANNA DÖBEREINER ${ }^{4}$
}

\begin{abstract}
RESUMO - Este trabalho objetivou selecionar bactérias diazotróficas isoladas de bananeira (Musa spp.) e avaliar sua influência no crescimento de mudas micropropagadas. Bactérias do tipo Herbaspirillum e relacionadas a Burkholderia cepacia foram inoculadas em plântulas de banana cv. Prata Anã e cv. Caipira. As bananeiras cv. Prata Anã, cultivadas in vitro com substrato pobre em N, apresentaram maior crescimento na presença de bactérias do tipo Herbaspirillum, ao passo que as bananeiras cv. Caipira cresceram melhor com o inóculo contendo bactérias do gênero Burkholderia. Em casa de vegetação, as bananeiras cv. Caipira crescidas em sacolas de plástico contendo areia e vermiculita (1:2), suplementada com a solução de Hoagland contendo $5 \mathrm{mg} \mathrm{L}^{-1}$ de $\mathrm{N}$, apresentaram maior crescimento quando da inoculação simultânea dos dois gêneros de bactérias, em comparação à inoculação individual. A inoculação simultânea proporcionou um crescimento nas bananeiras equivalente ao observado nas plantas-controles adubadas com $50 \mathrm{mg} \mathrm{L}^{-1}$ de $\mathrm{N}$ no substrato, porém o teor e o acúmulo de $\mathrm{N}$ na parte aérea das bananeiras foram menores. A contribuição de bactérias diazotróficas no crescimento de bananeiras é demonstrada pela primeira vez.
\end{abstract}

Termos para indexação: Herbaspirillum, Burkholderia, microrganismos, inoculação, Musa, plântulas, micropropagação, ecologia microbiana.

\section{DIAZOTROPHIC BACTERIA IN BANANA PLANTS}

\begin{abstract}
The objective of this work was to select strains of diazotrophic bacteria associated with banana plants and to determine micropropagated plantlet-growth-promotion by their inoculation with diazotrophs. Isolates of Herbaspirillum-like and Burkholderia cepacia related bacteria were inoculated in plantlets of banana cv. Prata Anã and the cultivar Caipira. Plantlets of banana cv. Prata Anã grown in vitro on a poor nitrogen substrate presented higher fresh weight when Herbaspirillum-like bacteria were used as inoculum, while the banana cv. Caipira grew better with the inoculation of Burkholderia cepacia related bacteria. Nevertheless, plants of the cultivar Caipira cultivated in plastic bags filled with sand and vermiculite (1:2) and supplied with Hoagland's solution containing $5 \mathrm{mg} \mathrm{L}^{-1}$ of $\mathrm{N}$ grew faster with the inoculation of Herbaspirillum-like and Burkholderia cepacia related bacteria. This effect was similar to $50 \mathrm{mg} \mathrm{L}^{-1}$ of $\mathrm{N}$ fertilizer added to the positive control. However, the control plants showed higher $\mathrm{N}$ content in their shoots when compared to bacterial inoculated plants. This work constitutes the first announcement of banana plant-growth-promotion by diazotrophic bacteria.
\end{abstract}

Index terms: Herbaspirillum, Burkholderia, microorganisms, inoculation methods, Musa, seedlings, micropropagation, microbial ecology.

\footnotetext{
${ }^{1}$ Aceito para publicação em 14 de janeiro de 2000.

Extraído da tese de doutorado apresentada à Universidade $\mathrm{Fe}$ deral Rural do Rio de Janeiro (UFRRJ) pelo primeiro autor.

${ }^{2}$ Eng. Agrôn., Dr., Embrapa-Centro Nacional de Pesquisa de Agroindústria Tropical (CNPAT), Rua Dra. Sara Mesquita, 2270, Caixa Postal 3761, CEP 60511-110 Fortaleza, CE. E-mail: weber@cnpat.embrapa.br

${ }^{3}$ Eng. Agrôn., Ph.D., Embrapa-Centro Nacional de Pesquisa de Agrobiologia (CNPAB), km 47, Caixa Postal 75505, CEP 23851-970 Seropédica, RJ.

${ }^{4}$ Eng. Agrôn., Ph.D. In memoriam.
}

\section{INTRODUÇÃO}

As bactérias fixadoras de nitrogênio de vida livre e associadas às plantas não leguminosas têm sido amplamente estudadas nas últimas décadas, desde o isolamento de Beijerinckia fluminense da rizosfera de cana-de-açúcar (Döbereiner \& Ruschel, 1958) e com a reidentificação de Azospirillum lipoferum isolado de raízes de diversas gramíneas forrageiras e cereais (Döbereiner \& Day, 1976). Várias novas espécies das 
bactérias diazotróficas têm sido isoladas de raízes e de partes aéreas de gramíneas (Döbereiner, 1992; Baldani et al., 1997), de plantas de tubérculo, como batata-doce (Paula, 1992) e mandioca (Balota, 1994), de cafeeiros (Jiménez-Salgado et al., 1998), bananeiras e abacaxizeiros (Weber et al., 1999). Bactérias do gênero Azospirillum também foram observadas na rizosfera de várias outras fruteiras tropicais (Rao, 1983; Ghai \& Thomas, 1989).

O potencial de fixação biológica de nitrogênio (FBN) tem sido destacado nas bactérias diazotróficas de caráter microaerofílico, incluindo espécies dos gêneros Azospirillum, Herbaspirillum, Acetobacter (Döbereiner, 1992) e Azoarcus (Reinhold-Hurek et al., 1993) e que colonizam partes internas das raízes e partes aéreas de gramíneas (Baldani et al., 1997). Bactérias microaerófilas, como as do gênero Burkholderia, têm sido isoladas de tecidos de gramíneas (Baldani, 1996), de plantas de mandioca (Balota, 1994) e de fruteiras (Weber et al., 1999), porém pouco se conhece sobre a sua contribuição ao crescimento das plantas.

A produção de substâncias reguladoras de crescimento de plantas tem sido observada em bactérias do gênero Azospirillum (Bashan \& Levanony, 1990; Okon \& Landera-Gonzalez, 1994; Bashan \& Holguin, 1997) e em outras bactérias diazotróficas, como as do gênero Burkholderia (Balota, 1994; Bevivino et al., 1994; Malik et al., 1997). Ainda, de acordo com Bevivino et al. (1994), isolados de Burkholderia cepacia são capazes de reduzir o crescimento de fungos fitopatogênicos em meio artificial.

A inoculação de bactérias diazotróficas será bastante facilitada em fruteiras, uma vez que a propagação dessas plantas é convencionalmente feita com mudas no viveiro. A micropropagação tem sido recomendada para fruteiras (Giacometti, 1990), principalmente para abacaxizeiros (Fitchet, 1990) e bananeiras (Mendes et al., 1996; Oliveira \& Silva, 1997; Souza et al., 1997) e poderia também facilitar a inoculação de bactérias diazotróficas nas plantas. A propagação em meio artificial in vitro visa eliminar os fitopatógenos das mudas (Cassells, 1991) e, assim, permite que as bactérias colonizem as plantas sem competição com outras bactérias.

O presente trabalho teve como objetivo selecionar estirpes de bactérias diazotróficas do tipo
Herbaspirillum e Burkholderia cepacia associadas com bananeiras, e avaliar sua influência no crescimento de mudas micropropagadas dessa fruteira.

\section{MATERIAL E MÉTODOS}

O crescimento de mudas de bananeira (Musa spp.) colonizadas pelas bactérias diazotróficas do tipo Herbaspirillum e Burkholderia cepacia foi avaliado em laboratório e em casa de vegetação na Embrapa-Centro Nacional de Pesquisa de Agrobiologia, em Seropédica, RJ. As bactérias diazotróficas utilizadas nos experimentos foram originalmente isoladas de bananeiras (BA) e abacaxizeiros (AB) adultos (Weber et al., 1999). As mudas das cultivares de banana Prata Anã (grupo AAB) e Caipira, anteriormente denominada Yangambi (grupo AAA), foram obtidas de meristemas de ápices caulinares, provenientes da Embrapa-Centro Nacional de Pesquisa de Mandioca e Fruticultura, Cruz das Almas, Bahia.

O estabelecimento e a adaptação dos explantes dos diferentes genótipos foram realizados em meio nutritivo MS (Murashige \& Skoog, 1962), suplementado com $30 \mathrm{~g} \mathrm{~L}^{-1}$ de sacarose e $7 \mathrm{~g} \mathrm{~L}^{-1}$ de ágar, ajustando-se o $\mathrm{pH}$ para 5,8. A sua multiplicação ocorreu no mesmo meio de cultura, suplementado com $2,5 \mathrm{mg} \mathrm{L}^{-1}$ de benzilaminopurina (BAP), e o enraizamento das plântulas da fruteira, no mesmo meio de adaptação.

Ao final da fase de enraizamento, cinco plântulas de cada genótipo de banana foram utilizadas para avaliar a presença de bactérias diazotróficas endofíticas, seguindose a metodologia descrita por Döbereiner et al. (1995). As demais plântulas foram utilizadas nos experimentos de inoculação de bactérias diazotróficas, após emitirem a terceira ou a quarta folha.

Foram conduzidos três experimentos com as mudas de bananeira: dois in vitro e um em casa de vegetação. Os tratamentos dos dois primeiros experimentos foram estabelecidos em agosto de 1996, utilizando-se tubos de vidro com capacidade de 90 a $100 \mathrm{~mL}$, tampados com rolhas de algodão e contendo em seu interior um substrato autoclavado. Esse substrato era formulado com $40 \mathrm{~mL}$ de solução de Hoagland sem N (Baldani, 1996) agarizado (7 $\mathrm{g} \mathrm{L}^{-1}$ de agar). Por sua vez, os tratamentos do experimento de casa de vegetação, montado em maio de 1997, foram aplicados em uma mistura de areia e vermiculita (proporção 1:2).

As bananeiras das cultivares Prata Anã (experimento 1) e Caipira (experimento 2) foram submetidas a nove tratamentos, sendo oito com misturas de inóculos de bactérias diazotróficas e um controle em que as bactérias estavam ausentes. A composição dos tratamentos foi: 1) $\mathrm{BA} 22+\mathrm{BA} 23$; 2) $\mathrm{BA} 10+\mathrm{BA} 11 ; 3) \mathrm{BA} 12$ + $\mathrm{BA} 14$; 
4) $\mathrm{BA} 123$ + $\mathrm{BA} 126 ; 5) \mathrm{BA} 22$ + $\mathrm{BA} 23$ + $\mathrm{BA} 123$ + $\mathrm{BA} 126$; 6) $\mathrm{BA} 10+\mathrm{BA} 11$ + $\mathrm{BA} 123$ + $\mathrm{BA} 126$; 7) $\mathrm{BA} 12$ + $\mathrm{BA} 14$ + BA123 + BA126; 8) mistura de todos os isolados anteriores; 9) o último inóculo esterilizado em autoclave (controle). Em ambos os experimentos utilizou-se o delineamento inteiramente casualizado e cinco repetições para cada tratamento. O crescimento das plantas no laboratório foi em condições de temperatura regulada para aproximadamente $29 \pm 2^{\circ} \mathrm{C}$, sob luz fluorescente e fotoperíodo de 14 horas.

As bactérias foram originalmente isoladas de bananeiras (Tabela 1), e os inóculos foram obtidos pelo crescimento de cada estirpe em meio líquido Dygs (Rodrigues Neto et al., 1986) modificado, sob agitação constante a $100 \mathrm{rpm}$, durante um período aproximado de 24 horas, sob temperatura de $30^{\circ} \mathrm{C}$. Após o crescimento, a densidade

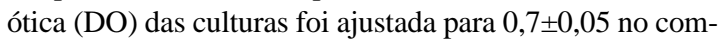
primento de onda de $600 \mathrm{~nm}$. Em seguida, as culturas foram misturadas de acordo com os tratamentos e as alíquotas de $1 \mathrm{~mL}$ (aproximadamente $10^{8}$ células viáveis) foram transferidas para os tubos de vidro.

Em seguida à transferência das plântulas e sua pesagem, os tubos receberam água esterilizada, para formar uma fina película sobre a superfície do substrato. Esse mesmo nível de água foi reposto, em média, a cada quatro dias, durante o período de condução dos experimentos. Ademais, semanalmente os tubos sofreram um rodízio de posição nas bandejas, e aos 25 dias as mudas receberam uma adubação suplementar com nitrato de amônio $\left(5 \mathrm{mg} \mathrm{L}^{-1}\right.$ de $\left.\mathrm{N}\right)$, para minimizar a deficiência do $\mathrm{N}$ nas plantas.

As bananeiras foram colhidas 75 dias após o transplante. Após a lavagem das plantas em água, as raízes foram separadas das partes aéreas (compostas de rizomas, pseudocaules e folhas) e pesadas as frações. Em seguida, separou-se aproximadamente $1 \mathrm{~g}$ de cada fração de duas plantas de todos os tratamentos em cada cultivar de bana- na; essas frações foram novamente lavadas em água esterilizada, maceradas e diluídas em série, nos tubos contendo $9 \mathrm{~mL}$ da solução salina com $1 / 4$ dos sais de $\mathrm{NFb}$, até $10^{-5}$. Alíquotas de $0,1 \mathrm{~mL}$ das diluições $\left(10^{-1}, 10^{-3}\right.$ e $\left.10^{-5}\right)$ foram transferidas em duplicata para os frascos com $5 \mathrm{~mL}$ de meio JNFb e/ou JMV (Baldani et al., 1986; Baldani, 1996). Após uma semana de incubação à temperatura de $30^{\circ} \mathrm{C}$, os frascos foram avaliados pela formação de películas características do crescimento das bactérias diazotróficas, conforme Döbereiner et al. (1995).

No experimento em casa de vegetação, utilizaram-se sacolas de plástico com $3 \mathrm{~L}$ da mistura de areia e vermiculita autoclavada, e as plântulas de banana cv. Caipira foram submetidas a 11 tratamentos, sendo nove com misturas de inóculos de bactérias diazotróficas e dois controles, sem e com $50 \mathrm{mg} \mathrm{L}^{-1}$ de $\mathrm{N}$ no substrato. A mistura aleatória de isolados de bactérias diazotróficas foi: 1) BA10 + BA11; 2) BA22 + BA23; 3) BA83 + BA86; 4) $\mathrm{BA} 123$ + $\mathrm{BA} 126$; 5) $\mathrm{BA} 10+\mathrm{BA} 11+\mathrm{BA} 22+\mathrm{BA} 23$ + $\mathrm{BA} 83$ + BA86; 6) $\mathrm{BA} 10$ + BA11 + $\mathrm{BA} 123$ + BA 126 ; 7) $\mathrm{BA} 22$ + BA 23 + BA123 + BA126; 8) $\mathrm{BA} 83$ + BA 86 + $\mathrm{BA} 123$ + BA126; 9) BA10 + BA11 + BA123 + BA126; 10) controle, contendo como inóculo a mistura de todos os isolados de bactérias, esterilizada em autoclave, sem fertilizante; 11) o controle acrescido da adubação com $50 \mathrm{mg} \mathrm{L}^{-1}$ de $\mathrm{N}$ no substrato. $\mathrm{O}$ experimento foi disposto no delineamento inteiramente casualizado, utilizando-se três repetições em cada tratamento.

$\mathrm{Na}$ obtenção dos inóculos das bactérias seguiu-se o procedimento descrito anteriormente, e as alíquotas de $2 \mathrm{~mL}$ (aproximadamente $2 \times 10^{8}$ células) das culturas (ajustadas na DO $0,7 \pm 0,05 \mathrm{em} 600 \mathrm{~nm}$ ) foram aplicadas sobre $2 \mathrm{~g}$ de turfa esterilizada, depositada no fundo de pequenas covas no centro de cada sacola de plástico.

Em seguida, cada sacola recebeu uma plântula de bananeira micropropagada, e após a irrigação do substrato com água desmineralizada e autoclavada os vasos foram

TABELA 1. Origem dos isolados de bactérias diazotróficas usados nos experimentos de inoculação das bananeiras. Seropédica, RJ, 1999.

\begin{tabular}{llll}
\hline Isolado & Cultivar - amostra & Local & Espécie (tipo) \\
\hline BA10 & Banana Butuhan - pseudocaules & Cruz das Almas (BA) & Herbaspirillum sp. (grupo 1) \\
BA11 & Banana Butuhan - folhas & Cruz das Almas (BA) & Herbaspirillum sp. (grupo 1) \\
BA12 & Banana Caipira - raízes & Cruz das Almas (BA) & Herbaspirillum sp. (grupo 2) \\
BA14 & Banana Caipira - pseudocaules & Cruz das Almas (BA) & Herbaspirillum sp. (grupo 2) \\
BA22 & Banana Prata Anã - folhas & Cruz das Almas (BA) & Herbaspirillum sp. (grupo 3) \\
BA23 & Banana Caipira - pseudocaules & Cruz das Almas (BA) & Herbaspirillum sp. (grupo 3) \\
BA83 & Banana Prata - pseudocaules & Itaguaí (RJ) & Herbaspirillum sp. (grupo 3) \\
BA86 & Banana D’água - folhas & Itaguaí (RJ) & Herbaspirillum sp. (grupo 3) \\
BA123 & Banana Prata Manteiga - raízes & Macaé (RJ) & Burkholderia cepacia (grupo 4) \\
BA126 & Banana D’água - raízes & Itaguaí (RJ) & Burkholderia cepacia (grupo 4) \\
\hline
\end{tabular}


cobertos com filme de plástico transparente, deixando-se de fora as plantas. A umidade do substrato foi restabelecida para próximo da capacidade máxima de retenção de água, em média, a cada quatro dias durante a condução do experimento. Mensalmente, as plantas receberam $100 \mathrm{~mL}$ da solução de Hoagland sem N (Baldani, 1996), e aos 30 dias, a adubação das plantas foi acrescida de nitrato de amônio ( $5 \mathrm{mg} \mathrm{L}^{-1}$ de $\mathrm{N}$ no substrato) nos dez primeiros tratamentos (sem a adubação nitrogenada inicial), para amenizar os sintomas de deficiência nutricional das plantas. A cada duas semanas, as sacolas também foram mudadas de posição nas bancadas.

A colheita das bananeiras foi realizada 60 dias após o transplante. Após a lavagem das plantas em água corrente, as raízes foram separadas das partes aéreas, compostas de rizomas, pseudocaules e folhas, e pesadas individualmente. Em seguida, frações de aproximadamente $1 \mathrm{~g}$ das raízes foram novamente lavadas em água esterilizada, maceradas, diluídas em série, e estas suspensões inoculadas em frascos contendo os meios semi-sólidos JNFb ou JMV (Baldani et al.,1986; Baldani, 1996), conforme foi descrito nos primeiros experimentos, para avaliar sua colonização pelas bactérias diazotróficas.

As partes aéreas foram secadas em estufa com ventilação forçada e ajustada na temperatura de $70^{\circ} \mathrm{C}$ durante o período de 72 horas e, após o resfriamento, pesadas e trituradas em moinho com peneira de 40 mesh, para a dosagem de $\mathrm{N}$ pelo método semimicro Kjeldahl (Bremner \& Mulvaney, 1982 citado por Oliveira, 1994).

Os incrementos de matéria fresca nas bananeiras crescidas in vitro e de matéria seca em condições de casa de vegetação foram determinados. Esses dados foram submetidos a análise de variância, e as médias dos tratamentos comparadas pelo teste de Tukey a $5 \%$ de probabilidade.

\section{RESULTADOS E DISCUSSÃO}

As plântulas de bananeiras propagadas in vitro não apresentaram nenhuma associação com bactérias diazotróficas que pudesse ser detectada pelo método do número mais provável durante a fase de enraizamento in vitro, confirmando, assim, a limpeza do material empregado (Tabela 2). A limpeza fitossanitária de plantas micropropagadas também foi destacada por Cassells (1991).

As bananeiras apresentaram crescimento diferenciado em resposta à inoculação de bactérias diazotróficas (Tabela 3). As plantas da cultivar Prata Anã que apresentaram massa fresca inicial de $0,591 \pm 0,175 \mathrm{~g}$, cujas diferenças não foram significativas pelo teste $\mathrm{F}$ a $1 \%$ de probabilidade, tiveram maior crescimento quando da inoculação com os isolados BA12 + BA14 de bactérias do tipo Herbaspirillum (tratamento 3), superando em $106,9 \%$ as plantas do tratamento controle. Por sua vez, a massa fresca total foi superior na presença de bactérias do tipo Herbaspirillum (tratamento 3), bactérias relacionadas a Burkholderia cepacia (tratamento 4) e misturas de ambos os gêneros de bactérias (tratamento 5) em relação ao controle e o tratamento contendo os isolados BA22 + BA23. As variações entre os dados de crescimento após a inoculação e os de matéria fresca total acumulada nas plantas podem ser atribuídas às pequenas diferenças não significativas na massa inicial das plantas. As variações no incremento da massa fresca das raízes também não foram significativas após a aplicação dos tratamentos, bem como a relação entre o peso da matéria fresca das raízes e a parte aérea das plantas. Modificações na morfologia de raízes e aumento da relação raiz/parte aérea têm sido observadas em plantas associadas com bactérias produtoras de fito-hormônios, a exemplo de Azospirillum (Bashan \& Levanony, 1990; Arshad \& Frankenberger Junior, 1991).

A colonização de raízes e partes aéreas das bananeiras, conseqüente da presença de isolados em meios semi-sólidos JNFb ou JMV, foi confirmada nos tratamentos que receberam inóculos contendo bactérias diazotróficas (Tabela 2). Foi observado o crescimento de bactérias em meios semi-sólidos nas diluições de $10^{-3}$ a $10^{-6}$ de amostras provenientes de tratamentos inoculadas, ao passo que nenhum crescimento foi detectado nas plantas-controles. Níveis similares de detecção foram observados em plantas de arroz quando da inoculação com bactérias dos gêneros Herbaspirillum e Burkholderia (Baldani, 1996). Plantas adultas de banana também suportam altas populações de bactérias (Weber et al., 1999).

Embora o nível máximo de detecção das bactérias diazotróficas tenha sido bastante uniforme entre os diferentes tratamentos, o crescimento das plantas foi diferente. Isto sugere que os grupos de bactérias diazotróficas diferem no grau de eficiência. Aqui, o grupo BA12 + BA14 de bactérias do tipo Herbaspirillum foi mais eficiente na promoção do crescimento de bananeiras cv. Prata Anã.

As bananeiras da cultivar Caipira apresentaram, na ocasião do estabelecimento dos tratamentos, 
$0,757 \pm 0,341 \mathrm{~g}$ de matéria fresca, e as diferenças foram não-significativas no teste $\mathrm{F}$ a $1 \%$ de probabilidade. Com a inoculação dos isolados BA123 + BA126 de bactérias relacionadas a Burkholderia cepacia (tratamento 4), as plantas apresentaram o maior crescimento, superando em $112,7 \%$ as plantas-controles. Destaca-se que esse grupo de bactérias tem afiliação genética com a espécie nova de bactérias diazotróficas (Weber et al., 1999), sendo nomeada Burkholderia brasilensis (Baldani, 1996). $\mathrm{O}$ incremento de matéria fresca das raízes foi superior na presença dessas bactérias e dos isolados BA123 + BA126 + BA23 + BA23 (tratamento 5), comparado ao controle. Esses incrementos relativos na matéria fresca das bananeiras cv. Caipira divergem dos dados obtidos da cultivar Prata Anã, o que dá indicação de uma relação diferenciada do efeito das bactérias diazotróficas sobre o crescimento de genótipos de bananeira.

Os níveis de detecção de bactérias diazotróficas foram bastante similares entre os tratamentos de inoculação, o que concorda com as observações feitas em relação à cultivar Prata Anã (Tabela 2). Os níveis de colonização das plantas sugerem que não há incompatibilidade na relação das bactérias do tipo Herbaspirillum e Burkholderia cepacia com as bananeiras. A falta de especificidade entre bactérias diazotróficas e plantas, como as bactérias do gênero Azospirillum e gramíneas, tem sido apontada como uma vantagem na obtenção de benefícios da associação (Bashan \& Holguin, 1997).

Da mesma forma que nos experimentos in vitro, a colonização das bananeiras pelas bactérias diazotróficas foi confirmada em casa de vegetação (Tabela 4). Nos tratamentos com inoculação, as bactérias foram detectadas nas diluições $10^{-3}$ e $10^{-6}$ quando amostras foram inoculadas em meios semisólidos JNFb ou JMV. Foi observada a presença de bactérias diazotróficas no tratamento-controle até a diluição $10^{-3}$ (meio $\mathrm{JNFb}$ ) e $10^{-2}$ (meio JMV), mas isso não invalidou os resultados obtidos. O nível de detecção das bactérias nos controles ocorreu numa diluição mais baixa que nos tratamentos com inoculação. A proximidade das plantas do tratamento-controle com as plantas submetidas a inoculação pode ter favorecido a contaminação durante a condução do experimento, uma vez que a morfologia das células e a fisiologia de crescimento das bactérias contaminantes nos meios semi-sólidos $\mathrm{JNFb}$ e JMV eram similares às das bactérias

TABELA 2. Diluições máximas com crescimento de bactérias diazotróficas em meios semi-sólidos JNFb e JMV de amostras de raízes e partes aéreas de bananeiras das cultivares Prata Anã (experimento 1) e Caipira (experimento 2) subordinadas aos tratamentos com inóculos de bactérias diazotróficas do tipo Herbaspirillum e Burkholderia cepacia. Médias de duas plantas. Seropédica, RJ, 1999.

\begin{tabular}{|c|c|c|c|c|c|c|c|c|c|}
\hline \multirow[t]{3}{*}{ Tratamento $^{1}$} & \multirow[t]{3}{*}{$\mathrm{N}^{\mathrm{o}}$} & \multicolumn{4}{|c|}{ Bananeira cv. Prata Anã } & \multicolumn{4}{|c|}{ Bananeira cv. Caipira } \\
\hline & & \multicolumn{2}{|c|}{ Raiz } & \multicolumn{2}{|c|}{ Parte aérea } & \multicolumn{2}{|c|}{ Raiz } & \multicolumn{2}{|c|}{ Parte aérea } \\
\hline & & $\mathrm{JNFb}$ & JMV & $\mathrm{JNFb}$ & JMV & $\mathrm{JNFb}$ & JMV & $\mathrm{JNFb}$ & JMV \\
\hline Herbaspirillum & $\begin{array}{l}1 \\
2 \\
3\end{array}$ & $\begin{array}{l}10^{-4} \\
10^{-5} \\
10^{-5}\end{array}$ & $\begin{array}{l}\mathrm{NA}^{2} \\
\mathrm{NA} \\
\mathrm{NA}\end{array}$ & $\begin{array}{l}10^{-5} \\
10^{-6} \\
10^{-6}\end{array}$ & $\begin{array}{l}\text { NA } \\
\text { NA } \\
\text { NA }\end{array}$ & $\begin{array}{l}10^{-3} \\
10^{-4} \\
10^{-5}\end{array}$ & $\begin{array}{l}\text { NA } \\
\text { NA } \\
\text { NA }\end{array}$ & $\begin{array}{l}10^{-5} \\
10^{-6} \\
10^{-6}\end{array}$ & $\begin{array}{l}\text { NA } \\
\text { NA } \\
\text { NA }\end{array}$ \\
\hline Burkholderia & 4 & NA & $10^{-6}$ & NA & $10^{-6}$ & NA & $10^{-5}$ & NA & $10^{-6}$ \\
\hline Misturas & $\begin{array}{l}5 \\
6 \\
7 \\
8\end{array}$ & $\begin{array}{l}10^{-3} \\
10^{-3} \\
10^{-3} \\
10^{-4}\end{array}$ & $\begin{array}{l}10^{-5} \\
10^{-5} \\
10^{-3} \\
10^{-6}\end{array}$ & $\begin{array}{l}10^{-5} \\
10^{-6} \\
10^{-4} \\
10^{-6}\end{array}$ & $\begin{array}{l}10^{-6} \\
10^{-6} \\
10^{-4} \\
10^{-6}\end{array}$ & $\begin{array}{l}10^{-3} \\
10^{-4} \\
10^{-3} \\
10^{-4}\end{array}$ & $\begin{array}{l}10^{-5} \\
10^{-3} \\
10^{-3} \\
10^{-3}\end{array}$ & $\begin{array}{l}10^{-3} \\
10^{-5} \\
10^{-6} \\
10^{-6}\end{array}$ & $\begin{array}{l}10^{-4} \\
10^{-4} \\
10^{-5} \\
10^{-4}\end{array}$ \\
\hline Controle & 9 & $\mathrm{ND}^{3}$ & ND & ND & ND & ND & ND & ND & ND \\
\hline
\end{tabular}

1 Tratamentos com inóculos de bactérias do tipo Herbaspirillum $(1=\mathrm{BA} 22+\mathrm{BA} 23 ; 2=\mathrm{BA} 10+\mathrm{BA} 11 ; 3=\mathrm{BA} 12+\mathrm{BA} 14)$, bactérias relacionadas a Burkholderia cepacia $(4=\mathrm{BA} 123+\mathrm{BA} 126)$, misturas de ambos os gêneros de bactérias $(5=\mathrm{BA} 22+\mathrm{BA} 23+\mathrm{BA} 123+\mathrm{BA} 126 ; 6=\mathrm{BA} 10+\mathrm{BA} 11+$ BA123 + BA126; 7 = BA12 + BA14 + BA123 + BA126; 8 = mistura de todos os isolados anteriores) e o controle (9).

2 Não avaliado.

3 Não detectado. 


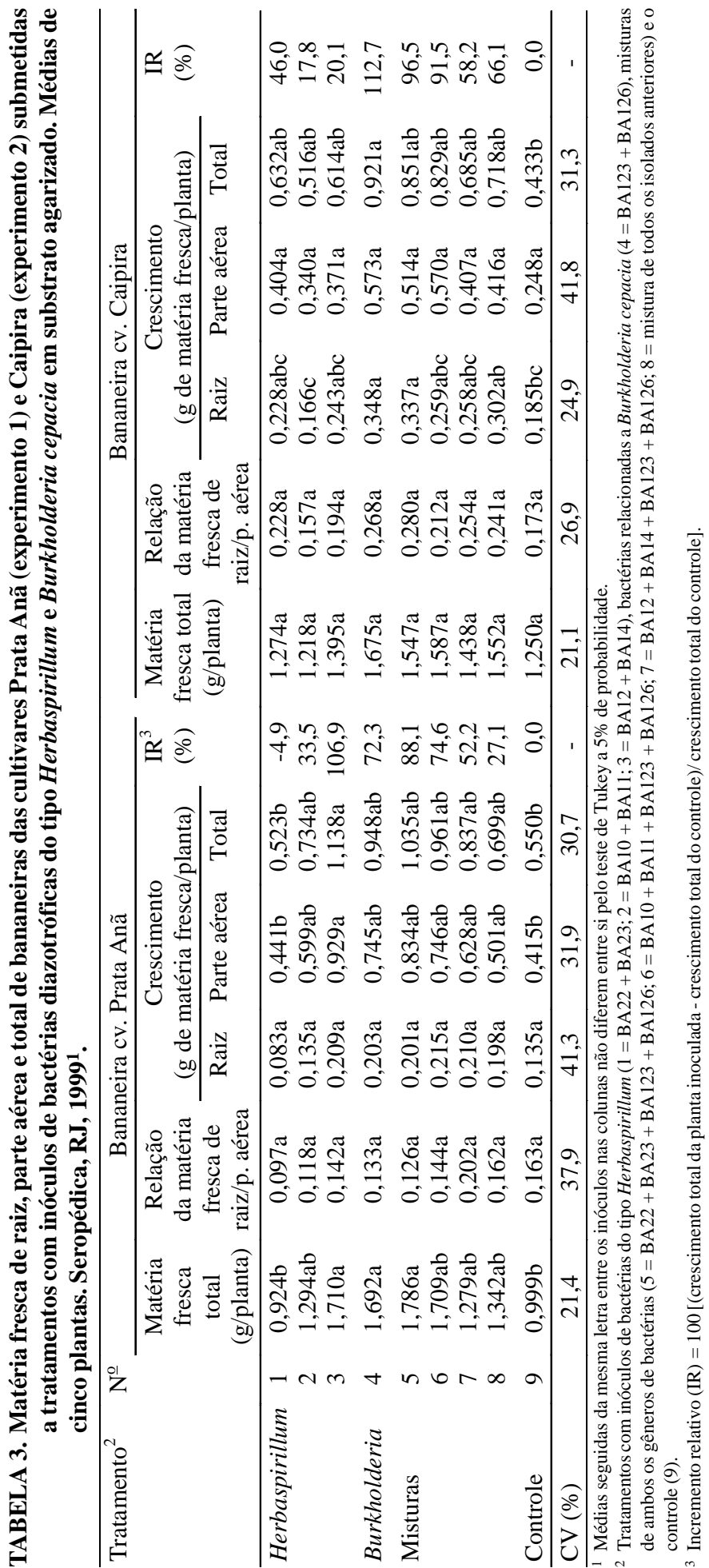

diazotróficas do tipo Herbaspirillum e Burkholderia sp. que foram utilizadas como inoculantes. A contaminação de plantas micropropagadas livres, pelo ar, é bastante comum em experimentos em casa de vegetação, sendo também observada em cereais com as espécies de Azospirillum (Bashan et al., 1991) e em cana-de-açúcar com Herbaspirillum (Olivares, 1997).

No experimento em casa de vegetação utilizando-se o substrato de areia e vermiculita, as bananeiras cv. Caipira apresentaram igualmente um crescimento diferenciado em resposta à inoculação de bactérias diazotróficas (Tabela 5). Observou-se que o tratamento 6 contendo a mistura de bactérias do tipo Herbaspirillum e Burkholderia cepacia (BA10 + BA11 + BA123 + BA126) foi mais eficiente na promoção do crescimento das plantas. Isto é uma indicação de que não houve competição entre os isolados dos dois gêneros de bactérias na associação com as bananeiras cv. Caipira. Deve ser considerado que, na ocasião do estabelecimento desse experimento, as plantas tiveram suas raízes podadas. Uma amostra dessas plântulas indicou $1,414 \pm 0,421 \mathrm{~g}$ de matéria fresca.

$\mathrm{O}$ maior incremento da matéria seca das raízes ocorreu no tratamento 6 , em que se inoculou a mistura das bactérias do tipo Herbaspirillum e Burkholderia cepacia $(\mathrm{BA} 10+\mathrm{BA} 11+\mathrm{BA} 123+$ BA126). Contudo, esse inóculo bacteriano não diferiu da inoculação dos isolados BA123 + BA126 (tratamento 4), $\mathrm{BA} 10+\mathrm{BA} 11+\mathrm{BA} 22+\mathrm{BA} 23+$ BA83 + BA86 (tratamento 5), BA22 + BA23 + BA123 + BA126 (tratamento 7) e BA83 + BA86 + BA123 + BA126 (tratamento 8), nem das plantas-controles que receberam a adubação de $50 \mathrm{mg} \mathrm{L}^{-1}$ de $\mathrm{N}$ no substrato. Uma tendência similar foi observada com a matéria seca aérea e total das plantas, à exceção do tra- 
TABELA 4. Diluições máximas com crescimento de bactérias diazotróficas em meios JNFb e JMV de amostras de raízes de bananeiras da cultivar Caipira subordinadas a tratamentos com inóculos de bactérias diazotróficas do tipo Herbaspirillum e Burkholderia cepacia. Médias de duas plantas. Seropédica, RJ, 1999.

\begin{tabular}{lrcc}
\hline Tratamento $^{1}$ & $\mathrm{~N}^{\mathrm{o}}$ & $\mathrm{JNFb}$ & $\mathrm{JMV}$ \\
\hline Herbaspirillum & 1 & $10^{-6}$ & $\mathrm{NA}^{2}$ \\
& 2 & $10^{-5}$ & $\mathrm{NA}$ \\
Burkholderia & 3 & $10^{-5}$ & $\mathrm{NA}$ \\
Misturas & 5 & $\mathrm{NA}$ & $10^{-6}$ \\
& 6 & $10^{-5}$ & $\mathrm{NA}$ \\
& 7 & $10^{-5}$ & $10^{-6}$ \\
& 8 & $10^{-5}$ & $10^{-3}$ \\
Controle & 9 & $10^{-4}$ & $10^{-3}$ \\
Controle $+\mathrm{N}$ & 10 & $10^{-4}$ & $10^{-3}$ \\
\hline
\end{tabular}

1 Tratamentos com inóculos de bactérias do tipo Herbaspirillum $(1=\mathrm{BA} 10+\mathrm{BA} 11 ; 2=\mathrm{BA} 22+\mathrm{BA} 23 ; 3=\mathrm{BA} 83+\mathrm{BA} 86)$, bactérias relacionadas a Burkholderia cepacia $(4=\mathrm{BA} 123+\mathrm{BA} 126)$, misturas de ambos os gêneros de bactérias $(5=\mathrm{BA} 10+\mathrm{BA} 11+\mathrm{BA} 22+\mathrm{BA} 23+$ $\mathrm{BA} 83+\mathrm{BA} 86 ; 6=\mathrm{BA} 10+\mathrm{BA} 11+\mathrm{BA} 123+\mathrm{BA} 126 ; 7=\mathrm{BA} 22+$ $\mathrm{BA} 23$ + BA 123 + BA126; $8=\mathrm{BA} 83$ + BA 86 + BA 123 + BA 126 $9=\mathrm{BA} 10+\mathrm{BA} 11+\mathrm{BA} 123+\mathrm{BA} 126)$ e os controles sem (10) e com adubação inicial de $50 \mathrm{mg} \mathrm{L}^{-1}$ de $\mathrm{N}$ (11).

2 Não avaliado. tamento 7, que não diferiu do controle sem adubação nitrogenada inicial. Esses dados sugerem que as bananeiras da cultivar Caipira podem ser substancialmente beneficiadas pela inoculação conjunta de bactérias do tipo Burkholderia cepacia e do tipo Herbaspirillum, a exemplo de isolados BA10 + BA11 + BA123 + BA126.

$\mathrm{O}$ teor de $\mathrm{N}$ na parte aérea das plantas variou com a inoculação e a adubação nitrogenada $\left(50 \mathrm{mg} \mathrm{L}^{-1}\right.$ de $\mathrm{N}$ no substrato) (Tabela 5). $\mathrm{O}$ conteúdo de $\mathrm{N}$ foi maior nas plantas adubadas, indicando que a contribuição da fixação biológica do $\mathrm{N}$ durante o período de crescimento das bananeiras foi bem menor. Aos 30 dias da inoculação, as plantas dos demais tratamentos já exibiam sintomas de deficiência do elemento. Teores menores de $\mathrm{N}$ também foram observados em plantas de batata-doce submetidas a inoculação de Acetobacter diazotrophicus, quando comparadas com as plantas-controles que receberam adubação nitrogenada (Paula, 1992). Olivares (1997) observou ainda menor quantidade de massa na parte aérea de plantas de cana-de-açúcar, quando da inoculação de estirpes de Herbaspirillum, comparadas ao controle adubado, com dose equivalente a $160 \mathrm{~kg} \mathrm{ha}^{-1}$ de N.

TABELA 5. Matéria fresca total, relação da matéria fresca de raiz e parte aérea, matéria seca de raiz, parte aérea e total, teor e $\mathrm{N}$-total na parte aérea de bananeiras cv. Caipira submetidas a tratamentos com inóculos de bactérias diazotróficas do tipo Herbaspirillum e Burkholderia cepacia em substrato com areia e vermiculita em sacolas de plástico. Médias de três plantas. Seropédica, RJ, 19991.

\begin{tabular}{|c|c|c|c|c|c|c|c|c|}
\hline Tratamento $^{2}$ & $\mathrm{~N}^{\mathrm{o}}$ & $\begin{array}{c}\text { Matéria } \\
\text { fresca total } \\
(\mathrm{g} / \mathrm{planta})\end{array}$ & $\begin{array}{c}\text { Relação da } \\
\text { matéria } \\
\text { fresca de } \\
\text { raiz/p. aérea }\end{array}$ & $\begin{array}{c}\text { Matéria } \\
\text { seca } \\
\text { de raiz } \\
\text { (g/planta) }\end{array}$ & $\begin{array}{l}\text { Matéria } \\
\text { seca de } \\
\text { p. aérea } \\
\text { (g/planta) }\end{array}$ & $\begin{array}{l}\text { Matéria } \\
\text { seca total } \\
\text { (g/planta) }\end{array}$ & $\begin{array}{c}\text { Teor } \\
\text { de N na } \\
\text { p. aérea } \\
(\%)\end{array}$ & $\begin{array}{c}\text { N-total } \\
\text { na p. aérea } \\
\text { (mg/planta) }\end{array}$ \\
\hline Herbaspirillum & $\begin{array}{l}1 \\
2 \\
3\end{array}$ & $\begin{array}{l}4,567 \mathrm{bc} \\
4,867 \mathrm{bc} \\
3,533 \mathrm{c}\end{array}$ & $\begin{array}{l}0,507 \mathrm{a} \\
0,640 \mathrm{a} \\
0,505 \mathrm{a}\end{array}$ & $\begin{array}{c}0,100 b \\
0,129 b \\
0,078 b\end{array}$ & $\begin{array}{l}0,299 \mathrm{bc} \\
0,281 \mathrm{bc} \\
0,214 \mathrm{c}\end{array}$ & $\begin{array}{c}0,399 b \\
0,410 b \\
0,293 b\end{array}$ & $\begin{array}{l}2,01 \mathrm{abc} \\
2,26 \mathrm{abc} \\
2,50 \mathrm{abc}\end{array}$ & $\begin{array}{l}6,025 b \\
5,634 b \\
5,275 b\end{array}$ \\
\hline Burkholderia & 4 & $6,567 \mathrm{abc}$ & $0,732 \mathrm{a}$ & $0,187 \mathrm{ab}$ & $0,423 a b c$ & $0,609 \mathrm{ab}$ & $1,70 b c$ & $6,429 b$ \\
\hline Misturas & $\begin{array}{l}5 \\
6 \\
7 \\
8 \\
9\end{array}$ & $\begin{array}{c}9,633 \mathrm{abc} \\
13,133 \mathrm{a} \\
6,400 \mathrm{abc} \\
6,933 \mathrm{abc} \\
3,567 \mathrm{c}\end{array}$ & $\begin{array}{l}0,815 \mathrm{a} \\
0,994 \mathrm{a} \\
0,874 \mathrm{a} \\
0,703 \mathrm{a} \\
0,471 \mathrm{a}\end{array}$ & $\begin{array}{l}0,274 \mathrm{ab} \\
0,416 \mathrm{a} \\
0,191 \mathrm{ab} \\
0,178 \mathrm{ab} \\
0,072 \mathrm{~b}\end{array}$ & $\begin{array}{l}0,568 \mathrm{abc} \\
0,763 \mathrm{a} \\
0,311 \mathrm{bc} \\
0,390 \mathrm{abc} \\
0,226 \mathrm{bc}\end{array}$ & $\begin{array}{l}0,842 \mathrm{ab} \\
1,178 \mathrm{a} \\
0,502 \mathrm{~b} \\
0,567 \mathrm{ab} \\
0,298 \mathrm{~b}\end{array}$ & $\begin{array}{l}1,74 \mathrm{bc} \\
1,32 \mathrm{c} \\
1,97 \mathrm{abc} \\
1,90 \mathrm{abc} \\
2,67 \mathrm{ab}\end{array}$ & $\begin{array}{r}9,903 \mathrm{~b} \\
10,057 \mathrm{~b} \\
5,969 \mathrm{~b} \\
7,589 \mathrm{~b} \\
5,605 \mathrm{~b}\end{array}$ \\
\hline $\begin{array}{l}\text { Controle } \\
\text { Controle }+\mathrm{N} \\
\end{array}$ & $\begin{array}{l}10 \\
11 \\
\end{array}$ & $\begin{array}{l}3,967 \mathrm{bc} \\
11,00 \mathrm{ab}\end{array}$ & $\begin{array}{l}0,717 \mathrm{a} \\
0,640 \mathrm{a} \\
\end{array}$ & $\begin{array}{l}0,111 \mathrm{~b} \\
0,280 \mathrm{ab}\end{array}$ & $\begin{array}{l}0,224 \mathrm{bc} \\
0,659 \mathrm{ab}\end{array}$ & $\begin{array}{l}0,324 \mathrm{~b} \\
0,939 \mathrm{ab}\end{array}$ & $\begin{array}{l}2,49 \mathrm{abc} \\
3,11 \mathrm{a}\end{array}$ & $\begin{array}{r}5,581 b \\
20,175 a \\
\end{array}$ \\
\hline $\mathrm{CV}(\%)$ & & 36,8 & 33,0 & 46,5 & 37,5 & 38,7 & 20,5 & 37,7 \\
\hline
\end{tabular}


Com o nível de adubação nitrogenada das bananeiras não houve déficit de $\mathrm{N}$ no substrato durante o estabelecimento da cultura. Assim, o crescimento das plantas proporcionado pelas bactérias diazotróficas pode ser atribuído principalmente à produção de substâncias fitorreguladoras. Segundo os pesquisadores Bashan \& Holguin (1997) e Malik et al. (1997), as bactérias diazotróficas podem mudar a morfologia das raízes e aumentar sua biomassa, habilitando as plantas a explorar melhor o volume do solo e absorver mais nutrientes.

A inoculação de bactérias diazotróficas em bananeiras micropropagadas é uma técnica a ser perseguida. O potencial das bactérias do tipo Herbaspirillum e Burkholderia cepacia, que naturalmente colonizam as bananeiras, está sendo demonstrado pela primeira vez.

\section{CONCLUSÕES}

1. A inoculação de bactérias diazotróficas do tipo Herbaspirillum e do tipo Burkholderia propiciam melhor crescimento de mudas micropropagadas de bananeiras.

2. A colonização de bactérias diazotróficas do tipo Herbaspirillum e Burkholderia ocorre em bananeiras das cultivares Prata Anã e Caipira.

3. Evidencia-se a contribuição de bactérias diazotróficas sobre o crescimento de bananeiras.

\section{REFERÊNCIAS}

ARSHAD, M.; FRANKENBERGER JUNIOR, W.T. Microbial production of plant hormones. Plant and Soil, Dordrecht, v.133, p.1-8, 1991.

BALDANI, J.I.; BALDANI, V.L.D.; SELDIN, L.; DÖBEREINER, J. Characterization of Herbaspirillum seropedicae gen. nov.: a rootassociated nitrogen-fixing bacterium. International Journal of Systematic Bacteriology, Reading, Grã-Bretanha, v.36, p.86-93, 1986.

BALDANI, J.I.; CARUSO, L.; BALDANI, V.L.D.; GOI, S.R.; DÖBEREINER, J. Recent advances in BNF with non-legume plants. Soil Biology \& Biochemistry, Oxford, v.29, p.911-922, 1997.

BALDANI, V.L.D. Efeito da inoculação de Herbaspirillum spp. no processo de colonização e infecção de plantas de arroz, e ocorrência e caracterização parcial de uma nova bactéria diazotrófica. Seropédica : UFRRJ, 1996. 238p. Tese de Doutorado.

BALOTA, E.L. Interação de bactérias diazotróficas e fungos micorrízicos arbusculares na cultura da mandioca (Manihot esculenta Crants). Itaguaí : UFRRJ, 1994. 281p. Tese de Doutorado.

BASHAN, Y.; HOLGUIN, G. Azospirillum plant relations: environmental and physiological advances (1990-1996). Canadian Journal of Microbiology, Ottawa, v.43, p.103-121, 1997.

BASHAN, Y.; LEVANONY, H. Current status of Azospirillum inoculation technology: Azospirillum as a challenge for agriculture. Canadian Journal of Microbiology, Ottawa, v.36, p.591-608, 1990.

BASHAN, Y.; LEVANONY, H.; WHITMOYER, R.E. Root surface colonization of non-cereal crop plants by pleomorphic Azospirillum brasilense Cd. Journal of General Microbiology, Reading, Grã-Bretanha, v.137, p.187-196, 1991.

BEVIVINO, A.; TABACCHIONI, S.; CHIARINI, L.; CARUSI, M.V.; DEL-GALLO, M.; VISCA, P. Phenotypic comparison between rhizosphere and clinical isolates of Burkholderia cepacia. Microbiology, Reading, Grã-Bretanha, v.140, p.1069-1077, 1994.

CASSELLS, A.C. Problems in tissue culture: culture contamination. In: DEBERGH, P.C.; ZIMMERMAN, R.H. (Ed.). Micropropagation: technology and application. Dordrecht : Kluver Academy, 1991. p.31-44.

DÖBEREINER, J. History and new perspectives of diazotrophs in association with non-leguminous plants. Symbiosis, Rehovot, v.13, p.1-13, 1992.

DÖBEREINER, J.; BALDANI, V.L.D.; BALDANI, J.I. Como isolar e identificar bactérias diazotróficas de plantas não-leguminosas. Brasília : EmbrapaSPI/Embrapa-CNPAB, 1995. 60p.

DÖBEREINER, J.; DAY, J.M. Associative symbioses in tropical grasses: characterization of microorganisms and nitrogen-fixing sites. In: INTERNATIONAL SYMPOSIUM ON NITROGEN FIXATION, 1., 1994, Pullman. Proceedings. Pullman : Washington State University, 1976. v.2, p.518-538. 
DÖBEREINER, J.; RUSCHEL, A.P. Uma nova espécie de Beijerinckia. Revista de Biologia, Lisboa, v.1, p.261-272, 1958.

FITCHET, M. Clonal propagation of queen and smooth cayenne pineapples. Acta Horticulturae, Leuven, n.275, p.261-266, 1990.

GHAI, S.K.; THOMAS, G.V. Occurrence of Azospirillum spp. in coconut-based farming systems. Plant and Soil, Dordrecht, v.114, p.235-241, 1989.

GIACOMETTI, D.C. Impacto atual da cultura de tecidos de plantas. In: TORRES, A.C.; CALDAS, L.S. (Ed.). Técnicas e aplicações de cultura de tecidos de plantas. Brasília : Associação Brasileira de Cultura de Tecidos de Plantas/Embrapa-CNPH, 1990. p.19-25.

JIMÉNEZ-SALGADO, T.; FUENTES-RAMIRES, L.E.; TAPIA-HERNANDES, A.; MASCARÚAESPERZA, M.A.; MARTINEZ-ROMERO, E.; CABALLERO-MELLADO, O. Coffea arabica L.: a new host plant for Acetobacter diazotrophicus and isolation of the nitrogen-fixing-acetobacteria. Applied of Environmental of Microbiology, Washington, v.63, p.3676-3683, 1998.

MALIK, K.A.; BILAL, R.; MEHNAZ, S.; RASUL, G.; MIRSA, M.S.; ALI, M.S. Association of nitrogenfixing, plant-growth-promoting rhizobacteria (PGPR) with kallar grass and rice. Plant and Soil, Dordrecht, v.194, p.37-44, 1997.

MENDES, B.M.J.; MENDES, F.J.; TULMANN NETO, A.; DEMETRIO, C.G.B.; PUSKE, O.R. Efficacy of banana plantlet production by micropropagation. Pesquisa Agropecuária Brasileira, Brasília, v.31, n.12, p.863-867, dez. 1996.

MURASHIGE, T.; SKOOG, F.A. Revised medium for rapid growth and bioassays with tobacco tissue cultures. Physiologia Plantarum, Copenhagen, v.15, p.473-497, 1962.

OKON, Y.; LANDERA-GONZALEZ, C.A. Agronomic applications of Azospirillum: an evaluation of 20 years worldwide field inoculation. Soil Biology \& Biochemistry, Oxford, v.26, p.1591-1601, 1994.

OLIVARES, F.L. Taxonomia, ecologia e mecanismos envolvidos na infecção e colonização de plantas de cana-de-açúcar (Saccharum sp. híbrido) por bactérias endofíticas do gênero Herbaspirillum. Seropédica : UFRRJ, 1997. Tese de Doutorado.

OLIVEIRA, O.C. Quantificação biológica de nitrogênio em arroz (Oryza sativa L.) inundado. Seropédica : UFRRJ, 1994. 135p. Dissertação de Mestrado.

OLIVEIRA, R.P. de; SILVA, S. de O. e. Avaliação da micropropagação comercial em bananeira. Pesquisa Agropecuária Brasileira, Brasília, v.32, n.4, p.415-420, abr. 1997.

PAULA, M.A. Interação micorrizas vesículoarbusculares-bactérias diazotróficas em batatadoce (Ipomoea batatas (L.) Lam. Itaguaí : UFRRJ, 1992. 168p. Tese de Doutorado.

RAO, N.S.S. Nitrogen-fixing bacteria associated with plantation and orchard plants. Canadian Journal of Microbiology, Ottawa, v.29, p.863-866, 1983.

REINHOLD-HUREK, B.; HUREK, T.; GILLIS, M.; HOSTE, B.; VANCANNEYT, M.; KERSTERS, K.; LEY, J. de. Azoarcus gen. nov., nitrogen-fixing Proteobacteria associated with roots of kallar grass (Leptochloa fusca (L.) Kunth), and description of two species, Azoarcus indigens sp. nov. and Azoarcus communis sp. nov. International Journal of Systematic Bacteriology, Reading, Grã-Bretanha, v.43, p.574-584, 1993.

RODRIGUES NETO, J.; MALAVOLTA JÚNIOR, V.A.; VICTOR, O. Meio simples para isolamento e cultivo de Xanthomonas campestris pv. citri tipo B. Summa Phytopatologica, Jaboticabal, v.12, p.16, 1986.

SOUZA, A.S.; DANTAS, J.L.L.; SOUZA, F.V.D.; CORDEIRO, Z.J.M.; SILVA NETO, S.P.S. Propagação. In: ALVES, E.J. (Ed.). A cultura da banana: aspectos técnicos, socioeconômicos e agroindustriais. Brasília : Embrapa-SPI/ Embrapa-CNPMF, 1997. p.151-195.

WEBER, O.B.; BALDANI, V.L.D.; TEIXEIRA, K.R.S.; KIRCHHOF, G.; BALDANI, J.I.; DÖBEREINER, $\mathrm{J}$. Isolation and characterization of diazotrophic bacteria from banana and pineapple plants. Plant and Soil, Dordrecht, v.210, p.103-113, 1999. 